\title{
THE MEASUREMENT OF GLOMERULAR AND TUBULAR PLASMA FLOW IN THE NORMAL AND DISEASED HUMAN KIDNEY ${ }^{1}$
}

\author{
By WALTER H. CARGILL 2 \\ (From the Department of Medicine, Duke University School of Medicine, Durham, N. C.)
}

(Received for publication October 18, 1948)

The clearance of para-aminohippuric acid (PAH) has been extensively used as a measure of the rate of renal plasma flow. The validity of this measurement depends upon the assumption that at low plasma levels PAH is completely extracted from the blood by tubular cells, and that therefore the only limiting factor to its rate of excretion in the urine is the rate at which it is delivered to the tubules. There is ample proof that this assumption is justified in normal man under basal conditions $(1,2)$. However, in any condition in which the total number or the functional capacity of tubular cells is decreased, the complete extraction of $\mathrm{PAH}$ and therefore the use of the clearance alone as a measure of renal plasma flow is open to serious question. The uncertainty as to the degree of renal impairment which is compatible with complete extraction of $\mathrm{PAH}$ has hampered the application of this method to the study of the diseased human kidney.

According to the Fick principle, the blood flow through an organ may be determined if the rate of consumption (or excretion) of a substance and the concentration of this substance in blood entering and leaving the organ (arterial-venous difference) are known. The application of the technique of venous catheterization to the sampling of blood from the renal vein in man (1) has made possible the utilization of this principle to determine the actual renal blood flow under conditions in which the extraction of $\mathrm{PAH}$ may not be completed.

In the normal kidney histological studies indicate that under most circumstances the blood flow through the tubules equals the blood flow through the glomeruli. In the diseased kidney either the glomeruli or tubules may be destroyed separately and there is no assurance from

1 Aided by a grant from the Life Insurance Medical Research Fund.

2 Present address: Department of Medicine, Emory University School of Medicine, Atlanta, Ga. histologic studies that glomerular flow. equals tubular flow. The glomerular flow can be measured from the rate of inulin excretion and the arterio-renal venous difference of inulin and compared with the tubular flow measured at the same time by the $\mathrm{PAH}$ excretion and arterio-renal venous $\mathrm{PAH}$ difference.

\section{METHODS}

The standard clearance procedures described by Goldring and Chasis (3) have been followed. Priming and sustaining infusions of inulin and sodium para-aminohippurate were given and urine collected by bladder catheterization at accurately timed intervals of 10-30 minutes. The dosage of PAH was adjusted to achieve an arterial blood level between 1 and $3 \mathrm{mg}$. per cent. An intravenous catheter was introduced into the right renal vein according to the procedure described by Warren, Brannon and Merrill (1). At approximately the midpoint of each urine collection period samples of renal venous and femoral arterial blood were withdrawn. The inulin and PAH content of plasma and urine were determined by the methods of Corcoran and Page (4) and Smith et al. (5), corrections being made for inulin blanks in plasma and urine. A 1:5 cadmium sulfate filtrate was used for PAH determinations in renal venous plasma instead of the 1:15 filtrate for arterial plasma. Paired samples of heparinized blood were obtained from each patient for hematocrit determinations.

\section{CALCULATIONS}

The application of the Fick principle to the determination of renal plasma flow in the dog from the excretion and extraction of PAH has been discussed by Phillips et al. (6). As we have not found any significant difference between arterial and renal venous hematocrit readings, nor between the PAH concentration of whole blood and plasma, we have not applied the corrections these authors suggest, but have used simply the formula (1) $R P F=\frac{U V}{A-R}$, where $U V$ is the rate of urinary excretion of $\mathrm{PAH}$ (mg./min.), and $\mathrm{A}$ and $\mathrm{R}$ represent the $\mathrm{PAH}$ concentrations in arterial and renal venous plasma (mg./cc.). The extraction of PAH was determined as the quotient of the arterial-renal venous PAH difference and the arterial level: (2) Ext. $=\frac{A-R}{A}$, and multiplied by 100 to express it as a percentage. The clearance 
of PAH was calculated in the usual manner from the rate of urinary excretion and the arterial level: (3) $\mathrm{C}_{\mathrm{PAB}}=\frac{\mathrm{UV}}{\mathrm{A}}$. It is evident from the integration of equations (1), (2) and (3) that the renal plasma flow may be obtained by dividing the clearance of $\mathrm{PAH}$ by its extraction: (4) $\mathrm{RPF}=\frac{\mathrm{UV}}{\mathrm{A}-\mathrm{R}}=\frac{\mathrm{C}_{\mathrm{PAB}}}{\text { Ext. PAH }}$.

Since inulin is a foreign substance which is neither metabolized nor stored by the kidney, substitution of inulin concentrations in the above formulae should also yield a valid estimate of renal plasma flow. According to the available evidence, inulin is excreted entirely by glomerular filtration, whereas the excretion of PAH is accomplished largely by active tubular transfer. The value for renal plasma flow obtained from inulin concentrations should represent therefore only the volume of plasma which perfuses the glomeruli and, derived from PAH clearance and extraction, the flow through both glomeruli and tubules, predominantly the latter. These determinations may therefore be designated glomerular plasma flow (GPF) and tubular plasma flow (TPF).

The filtration fraction (FF) represents the fraction of plasma water which is filtered at the glomerulus, and has been determined by us as the ratio of the inulin clearance to the tubular plasma flow: $\mathrm{FF}=\frac{\mathrm{C}_{\mathrm{IN}}}{\mathrm{TPF}}$. If glomerular and tubular plasma flows are equal, the filtration fraction should equal the inulin extraction as obtained from Equation (2).

This derivation of the filtration fraction differs from that usually given, as other investigators have used this term to represent the ratio of the inulin clearance to the PAH clearance alone. Our values for FF are therefore lower than those previously reported.

All figures have been corrected to a surface area of 1.73 sq. $\mathrm{m}$.

\section{RESULTS}

Data on ten subjects who were hospitalized for minor illnesses unrelated to the kidney, and who had normal blood pressures, are summarized in Table I. The subjects with abnormal renal function have been divided into two groups: those in whom vascular changes might be considered primary, and those in whom disturbances of renal circulation might be considered secondary to glomerular dysfunction. The first group (Table II) includes patients whose predominant complaint was high blood pressure. In some of these impairment of renal function was manifested clinically by albuminuria, hyposthenuria, and decreased phenolsulfonphthalein excretion. Others presented only a history of elevated blood pressure for six months or more. Two patients who were diagnosed clinically as chronic pyelonephritis are also included in this group.

The second group (Table III) is composed entirely of subjects with acute, subacute or chronic glomerulonephritis.

There are many possible objections to this division of subjects. The variety of structural changes which may be produced in the kidney by any one of these disease processes is reflected in the disagreement of authorities as to their pathological classification. The existence of diffuse arteriolar disease in chronic glomerulonephritis is well recognized, as is the fact that extensive glomerular changes occur in nephrosclerosis. A functional basis for the clinical classification of these patients is revealed, however, in the values found for the filtration fraction. As demonstrated in Figure 1, there is a sharp division between the patients with hypertensive disease of the kidney and those with glomerulonephritis; the former lying above, and

TABLE.I

Normal subjects

\begin{tabular}{|c|c|c|c|c|c|c|c|c|}
\hline Pt. & $C_{I N}$ & $\begin{array}{c}\text { Inulin } \\
\text { extraction }\end{array}$ & GPF & $\mathrm{C}_{\text {PAH }}$ & $\underset{\text { extraction }}{\text { PAH }}$ & TPF & FF & Diagnosis \\
\hline E. F. & $\begin{array}{c}c c . / \min . \\
112\end{array}$ & $\begin{array}{c}\text { per cent } \\
24.6\end{array}$ & $\begin{array}{c}c c . / \min \\
450\end{array}$ & $\begin{array}{c}\text { cc./min } \\
544\end{array}$ & $\begin{array}{c}\text { per cent } \\
83\end{array}$ & $\begin{array}{c}c c . / \min . \\
659\end{array}$ & $\begin{array}{c}\text { per cent } \\
17.0\end{array}$ & $\begin{array}{l}\text { Bromide Intoxication. (Con- } \\
\text { valescent) }\end{array}$ \\
\hline $\begin{array}{l}\text { A. J. } \\
\text { W. W. } \\
\text { E. W. } \\
\text { R. B. } \\
\text { J. H. } \\
\text { L. G. } \\
\text { M. A. C. } \\
\text { R. M. } \\
\text { W. F. W. }\end{array}$ & $\begin{array}{r}115 \\
106 \\
107 \\
92 \\
131 \\
112 \\
142 \\
133 \\
120\end{array}$ & $\begin{array}{l}11.6 \\
14.5 \\
14.1 \\
19.7 \\
20.7 \\
12.3 \\
- \\
-\end{array}$ & $\begin{array}{l}990 \\
730 \\
759 \\
467 \\
633 \\
895 \\
- \\
-\end{array}$ & $\begin{array}{l}595 \\
716 \\
595 \\
519 \\
527 \\
730 \\
764 \\
652 \\
742\end{array}$ & $\begin{array}{l}89 \\
93 \\
91 \\
86 \\
92 \\
92 \\
91 \\
90 \\
90\end{array}$ & $\begin{array}{l}668 \\
770 \\
653 \\
604 \\
573 \\
794 \\
840 \\
725 \\
825\end{array}$ & $\begin{array}{l}17.0 \\
14.0 \\
16.4 \\
15.2 \\
22.9 \\
13.9 \\
16.9 \\
18.2 \\
13.6\end{array}$ & $\begin{array}{l}\text { Rheumatoid Arthritis } \\
\text { Multiple Sclerosis } \\
\text { Psychoneurosis } \\
\text { Fibromyositis } \\
\text { Peptic Ulcer } \\
\text { Psychoneurosis } \\
\text { Peptic Ulcer } \\
\text { Primary Optic Atrophy } \\
\text { Multiple Sclerósis }\end{array}$ \\
\hline Mean & 117 & 16.8 & 703 & 638 & 90 & 710 & 16.5 & \\
\hline
\end{tabular}


TABLE II

Vascular diseases

\begin{tabular}{|c|c|c|c|c|c|c|c|c|}
\hline Pt. & $\mathrm{C}_{\mathrm{IN}}$ & $\underset{\text { extraction }}{\text { Inulin }}$ & GPF & $\mathrm{C}_{\text {PAH }}$ & $\underset{\text { extraction }}{\text { PAH }}$ & TPF & FF & Diagnosis \\
\hline $\begin{array}{l}\text { R. L. } \\
\text { C. M. } \\
\text { B. G. } \\
\text { M. S. } \\
\text { E. T. } \\
\text { C. E. } \\
\text { L. M. } \\
\text { N. W. } \\
\text { B. H. } \\
\text { G. H. } \\
\text { L. H. }\end{array}$ & $\begin{array}{c}c c . / m i n . \\
109 \\
143 \\
133 \\
109 \\
97 \\
70 \\
54 \\
50 \\
36 \\
36 \\
20\end{array}$ & $\begin{array}{c}\text { per cent } \\
21.5 \\
26.3 \\
17.2 \\
21.4 \\
26.3 \\
25.7 \\
14.1 \\
17.9 \\
20.3 \\
15.0 \\
10.3\end{array}$ & $\begin{array}{c}c c . / m i n . \\
507 \\
544 \\
773 \\
509 \\
369 \\
272 \\
383 \\
280 \\
177 \\
240 \\
194\end{array}$ & $\begin{array}{cc}c c . / m i n . \\
421 \\
588 \\
494 \\
376 \\
276 \\
266 \\
222 \\
206 \\
110 \\
102 \\
83\end{array}$ & $\begin{array}{c}\text { per cent } \\
90 \\
90 \\
91 \\
87 \\
80 \\
86 \\
76 \\
75 \\
58 \\
64 \\
73\end{array}$ & $\begin{array}{c}c c . / m i n . \\
468 \\
654 \\
545 \\
432 \\
345 \\
310 \\
292 \\
275 \\
190 \\
159 \\
114\end{array}$ & $\begin{array}{c}\text { per cent } \\
23.3 \\
21.9 \\
24.4 \\
25.2 \\
28.1 \\
22.6 \\
18.5 \\
18.2 \\
19.0 \\
22.6 \\
17.5\end{array}$ & $\begin{array}{l}\text { Essential Hypertension } \\
\text { Essential Hypertension } \\
\text { Post-Toxemic Hypertension } \\
\text { Essential Hypertension } \\
\text { Nephrosclerosis } \\
\text { Nephrosclerosis } \\
\text { Nephrosclerosis } \\
\text { Chronic Pyelonephritis } \\
\text { Nephrosclerosis } \\
\text { Nephrosclerosis } \\
\text { Chronic Pyelonephritis }\end{array}$ \\
\hline Mean & 78 & 19.6 & 386 & 285 & 79 & 344 & 21.9 & \\
\hline
\end{tabular}

the latter below the normal mean. The two patients with chronic pyelonephritis were found to have filtration fractions similar to the patients with nephrosclerosis with comparable degrees of renal damage.

It may be seen from Tables II and III that the extraction of PAH remains within the normal range (83-93 per cent) until renal damage is moderately advanced. The number of determinations is insufficient to allow quantitative assessment of the degree of renal impairment which is incompatible with the complete extraction of $\mathrm{PAH}$ at low plasma levels. It appears, however, from these data that PAH extraction does not begin to decrease until the inulin clearance has fallen below
$60 \mathrm{cc} . / \mathrm{min}$. and PAH clearance below $300 \mathrm{cc}$ // min. Figure 2 is a graphic representation of the latter relationship.

Estimates of glomerular and tubular plasma flow, as determined from the clearance and extraction of inulin and $\mathrm{PAH}$, are given in the tables and compared in Figure 3. The correlation between the two determinations in individual patients is often poor (particularly in patients D. R. and A. J.), but in general the ratio of the values approaches unity. Less divergence is found when mean values are considered. For all 28 patients in whom comparisons were made, the mean rate of glomerular plasma flow was $497 \mathrm{cc}$./min., and the mean rate of tubular plasma flow $466 \mathrm{cc}$./min.

TABLE III

Glomerulonephritis

\begin{tabular}{|c|c|c|c|c|c|c|c|c|}
\hline Pt. & $\mathrm{C}_{\mathrm{IN}}$ & $\underset{\text { extraction }}{\text { Inulin }}$ & GPF & $\mathrm{C}_{\mathrm{PAH}}$ & $\underset{\text { extraction }}{\text { PAH }}$ & TPF & FF & Diagnosis \\
\hline G. W. & $\begin{array}{c}c c . / m i n . \\
67\end{array}$ & $\begin{array}{c}\text { per cent } \\
12.7\end{array}$ & $\begin{array}{c}c c . / m i n \\
528\end{array}$ & $\begin{array}{c}c c . / m i n \\
444\end{array}$ & $\begin{array}{c}\text { per cent } \\
89\end{array}$ & $\begin{array}{c}c c . / \min . \\
499\end{array}$ & $\begin{array}{c}\text { per cent } \\
13.4\end{array}$ & Subacute Glomerulonephritis. \\
\hline $\begin{array}{l}\text { D. R. } \\
\text { A. H. } \\
\text { W. H. }\end{array}$ & $\begin{array}{l}45 \\
77 \\
51\end{array}$ & $\begin{array}{l}12.8 \\
14.1 \\
10.2\end{array}$ & $\begin{array}{l}352 \\
546 \\
500\end{array}$ & $\begin{array}{l}519 \\
550 \\
440\end{array}$ & $\begin{array}{l}86 \\
90 \\
79\end{array}$ & $\begin{array}{l}604 \\
612 \\
557\end{array}$ & $\begin{array}{r}7.5 \\
12.4 \\
9.2\end{array}$ & $\begin{array}{l}\text { Aubacute Glomerulonephritis } \\
\text { Acute Glomerulonephritis } \\
\text { Acute Exacerbation of Chronic }\end{array}$ \\
\hline B. B. & 78 & 9.1 & 857 & 592 & 80 & 740 & 10.4 & Chronic Glomerulonephritis; \\
\hline G. I. & 83 & 7.5 & 1106 & 696 & 86 & 810 & 10.2 & Subacute Glomerulonephritis; \\
\hline P. M. & 85 & 7.1 & 1196 & 932 & 82 & 1135 & 7.5 & $\begin{array}{l}\text { Nephrotic Stage } \\
\text { Chronic Glomerulonephritis; }\end{array}$ \\
\hline $\begin{array}{l}\text { R. E. } \\
\text { B. R. } \\
\text { J. M. } \\
\text { M. C. }\end{array}$ & $\begin{array}{l}76 \\
17 \\
56 \\
12\end{array}$ & $\begin{array}{l}13.0 \\
7.6 \\
=\end{array}$ & $\begin{array}{l}585 \\
224 \\
-\end{array}$ & $\begin{array}{r}373 \\
121 \\
293 \\
90\end{array}$ & $\begin{array}{l}82 \\
50 \\
64 \\
35\end{array}$ & $\begin{array}{l}455 \\
242 \\
458 \\
257\end{array}$ & $\begin{array}{r}16.7 \\
7.0 \\
12.2 \\
4.7\end{array}$ & $\begin{array}{l}\text { Chronic Glomerulonephritis } \\
\text { Chronic Glomerulonephritis } \\
\text { Chronic Glomerulonephritis } \\
\text { Chronic Glomerulonephritis }\end{array}$ \\
\hline Mean & 56 & 10.2 & 614 & 423 & 70 & 545 & 10.3 & \\
\hline
\end{tabular}




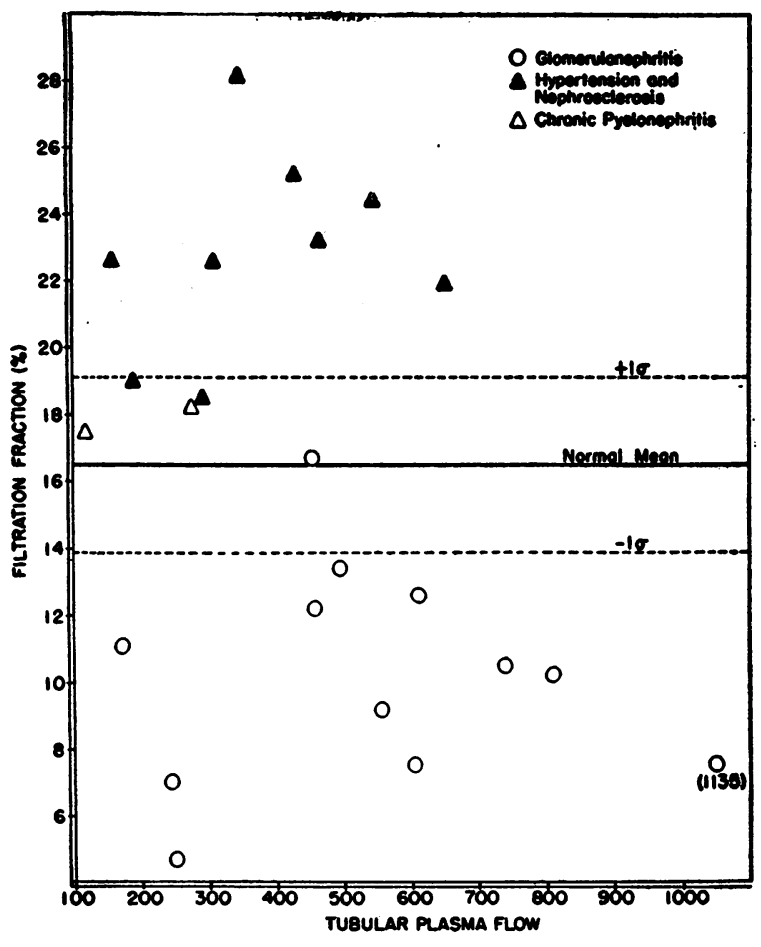

Fig. 1. Filtration Fraction Values in Patients with Hypertensive Disease of Kidney and with GLOMERULONEPHRITIS

We consider this convergence of the means to indicate that the individual differences are random and probably not significant, although the heterogeneity of the sample does not permit statistical analysis.

We have found greater fluctuations in the inulin concentrations of successive samples of renal venous blood than in the corresponding arterial samples. This phenomenon is being investigated further, as we feel that it may indicate some intermittency of glomerular filtration.

\section{DISCUSSION}

The application of clearance and saturation methods to the study of diseased kidneys has yielded much valuable information. Characteristic functional patterns in various renal disorders have been described $(7,8)$, involving chiefly alterations in the ratio of glomerular filtration to the mass of actively functioning tubular tissue. Less is known concerning disturbances of renal circulation in abnormal human kidneys, for the reasons set forth in the introduction to this article.

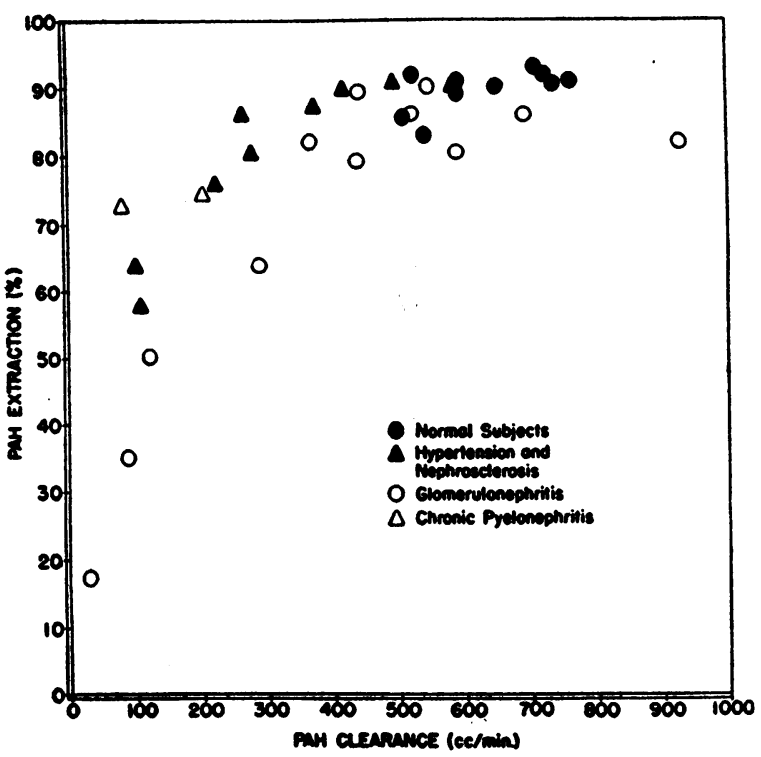

Fig. 2. PAH Extraction and PAH Clearance in Normal Subjects and in Patients with Hypertension, Glomerulonephritis and Chronic PyelonephriTIS

The present investigation has been concerned with the determination of cortical blood flow from the excretion and extraction of inulin and PAH. On theoretical grounds, agreement might be expected in normal subjects between the values ob-

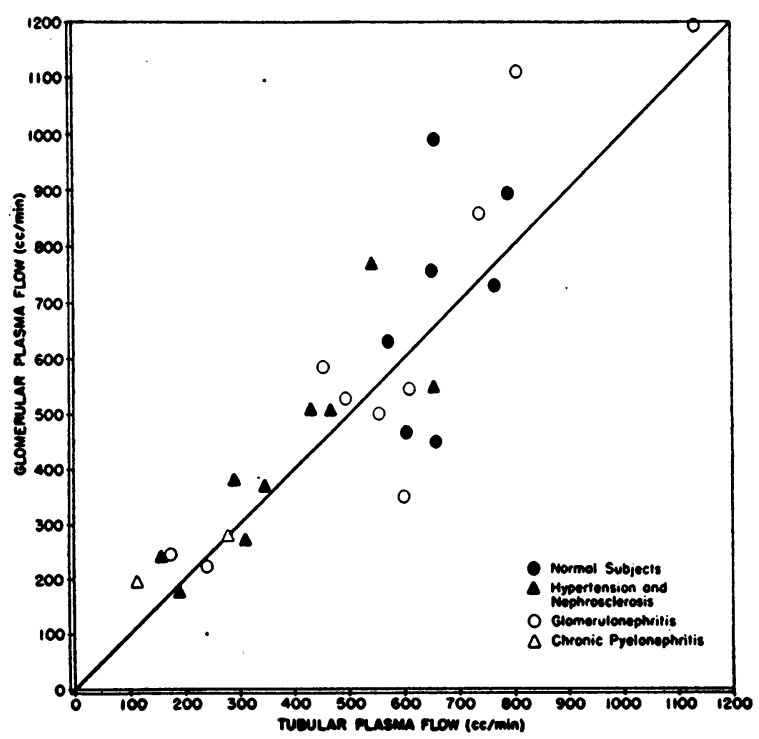

Fig. 3. Glomerular and Tubular Plasma Flow Determinations iń Normal Subjects and in Patients with Hypertension, Glomerulonephritis and Chronic Pyelonephritis 
tained by using these two compounds. White and Heinbecker (9) found in the dog that determinations of renal plasma flow from the clearance and extraction of inulin and diodrast differed by less that 10 per cent. Reubi (10), however, has recently claimed that in man estimations of plasma flow from mannitol and PAH clearance and extraction do not agree. Our data show essential agreement between inulin and $\mathrm{PAH}$ determinations of plasma flow in seven subjects with normal renal function.

The morphologic studies of Dehoff (11) and of Oliver (12) indicate that an extensive reorganization of the vascular pattern of the cortex takes place in the late stages of both nephrosclerosis and glomerulonephritis. Whereas in the normal kidney the tubules are supplied only with postglomerular blood, in the diseased kidney numerous channels are to be found through which blood may pass directly from an interlobular artery or afferent arteriole to a peritubular capillary. The development of these vascular short-circuits has been associated by Oliver with the loss of the normal functional predominance of the glomerulus and the appearance of relatively aglomerular tubules. Smith (13) has postulated the existence of "impotent nephrons" lacking tubular activity, through which glomerular filtrate may pass unchanged to collecting ducts.

It is conceivable that an extensive disturbance in the balance between glomerular and tubular blood supply might be reflected in a disproportion between the rates of plasma flow as estimated from inulin and from PAH excretion and extraction (GPF and TPF). We have not found such a disproportion, even in severely diseased kidneys. It is true, of course, that the methods employed yield only an estimate of the total blood supply of all functioning glomeruli and tubules, and it is manifestly impossible to detect from our data any dissociation of flow between the parts of individual nephrons. The results show only that the overall rates of perfusion of glomerular and tubular tissue are similar. This is not necessarily an index of the relative size or spatial relation of these segments. Smith (13) has pointed out that the circulation of interstitial fluid in the kidney makes possible the extraction of diodrast by tubular cells located at a distance from the glomerulus where the filtration of inulin took place. It is probable that the values we have found in abnormal kidneys represent the means of a variety of rates of flow corresponding to the areas of atrophy and hypertrophy which figure so prominently in microscopic sections of the diseased cortex. The absence of an appreciable difference between rates of plasma flow as determined by inulin and by $\mathrm{PAH}$ makes it highly unlikely, however, that the adaptive and regressive changes described by Oliver are associated with any significant redistribution of the blood supply between glomerular and tubular tissue. The only alternative is to assume that in the kidneys under discussion inulin may be excreted by tubular cells or that $\mathrm{PAH}$ is excreted entirely by glomerular filtration. The different degrees of clearance and extraction of these substances make either of these possibilities highly unlikely.

Raaschou (14) has pointed out that in diseased kidneys the filtration fraction as calculated from clearances alone is an artificial concept, meaning only the relation between the volume of filtered fluid in the glomeruli and the amount of plasma flowing past active secretory tissue. The same objection might be raised to the use of the ratio of filtration rate to the minimal renal plasma flow as determined from PAH clearance and extraction. Since, however, the filtration fraction so derived equalled the observed extraction of inulin, we feel that it is a valid concept even in diseased kidneys, representing the actual fraction of plasma water filtered at the glomeruli.

A low filtration fraction in the early and moderately advanced stages of glomerulonephritis has been noted previously by other workers $(7,8,15)$. We have found that the filtration fraction remains low even in the late stages of this disease. This finding emphasizes the predominantly glomerular localization of the morbid process throughout its course, and suggests that the decreased circulation found late in the disease is secondary to glomerular obliteration. In the acute and subacute stages of glomerulonephritis, particularly in the nephrotic stage, a low filtration rate may be the only functional abnormality noted. A few of these patients actually showed an increased renal blood flow as measured both by inulin and by $\mathrm{PAH}$.

In contrast is the elevation of the filtration fraction in patients with hypertension and hypertensive disease. Here the abnormality is primarily vascu- 
lar in origin. Smith and his associates believe that the maintenance of the filtration rate with a decrease in blood flow is due to functional constriction of the efferent glomerular arteriole. Our observations suggest that the filtration fraction tends to fall as the vascular disease progresses. This fall may represent the addition of occlusive changes in the afferent arteriole which counteract the efferent vasoconstriction and lower the intraglomerular pressure.

The recent demonstration by Trueta et al. (16) of arterio-venous shunts in the rabbit kidney has given rise to much speculation as to the existence and importance of these shunts in man. If blood is shunted away from the cortex through juxtamedullary channels the extraction of PAH should fall. This has been found to happen in rabbits (17). Our data indicate that in the diverse conditions studied $\mathrm{PAH}$ extraction was not decreased until renal damage was moderately advanced, suggesting that the Trueta mechanism is not operative in the early stages of hypertension and glomerulonephritis under resting conditions.

\section{SUMMARY AND CONCLUSIONS}

1. Glomerular plasma flow (GPF) has been estimated from the rate of urinary excretion and the arterial- renal venous inulin difference, and compared with the tubular plasma flow (TPF) obtained from the excretion and renal extraction of sodium para-aminohippurate in normal subjects and in patients with varying degrees of renal impairment.

2. The general agreement between the values obtained for GPF and TPF indicates that there is no extensive dissociation of glomerular and tubular circulation, even in advanced renal disease.

3. The ratio of glomerular filtration rate to renal plasma flow (filtration fraction) is lower than the normal mean in all stages of glomerulonephritis, and higher than normal in nephrosclerosis and chronic pyelonephritis.

The author wishes to thank Dr. E. A. Stead, Jr., for advice and encouragement, and the following for technical assistance: Miss Eloise Covington, Miss Hodge Person and Mrs. Juanita M. Clontz.

\section{BIBLIOGRAPHY}

1. Warren, J. V., Brannon, E. S., and Merrill, A. J., Method of obtaining renal venous blood in unanesthetized persons with observations on extrac- tion of oxygen and sodium para-amino hippurate. Science, 1944, 100, 108.

2. Bradley, S. E., Curry, J. J., and Bradley, G. P., Renal extraction of $p$-aminohippurate in normal subjects and in essential hypertension and chronic diffuse glomerulonephritis. Federation Proc., 1947, 6, 79.

3. Goldring, W., and Chasis, H., Hypertension and Hypertensive Disease. The Commonwealth Fund, New York, 1944.

4. Corcoran, A. C., and Page, I. H., Applications of diphenylamine in determination of levulose in biological media; determination of inulin; determination of levulose in small amounts of blood. J. Biol. Chem., 1939, 127, 601.

5. Smith, H. W., Finkelstein, N., Aliminosa, L., Crawford, B., and Graber, M., The renal clearances of substituted hippuric acid derivatives and other aromatic acids in dog and man. J. Clin. Invest., 1945, 24, 388.

6. Phillips, R. A., Dole, V. P., Hamilton, P. B., Emerson, K., Archibald, R. M., and Van Slyke, D. D., Effects of acute hemorrhagic and traumatic shock on renal function of dogs. Am. J. Physiol., 1946, 145, 314.

7. Earle, D. P., Taggert, J. V., and Shannon, J. A., Glomerulonephritis: a survey of the functional organization of the kidney in various stages of diffuse glomerulonephritis. J. Clin. Invest., 1944, 23, 119.

8. Corcoran, A. C., Taylor, R. D., and Page, I. H., Functional patterns in renal disease. Ann. Int. Med., 1948, 28, 560.

9. White, H. L., and Heinbecker, P., Observations on inulin and diodrast clearances and on renal plasma flow in normal and hypophysectomized dogs. Am. J. Physiol., 1940, 130, 464.

10. Reubi, F. C., The renal extraction of mannitol and para-aminohippurate compared to their excretions in normotensive and hypertensive subjects. J. Clin. Invest., 1948, 27, 553.

11. Dehoff, E., Die Arteriellen Zuflusse des Capillarsystems in der Nierenrinde des Menschen. Virchow's Arch. f. path. Anat., 1920, 228, 134.

12. Oliver, Jean, Architecture of the Kidney in Chronic Bright's Disease. Paul B. Hoeber, Inc., New York, 1939.

13. Smith, H. W., Note on the interpretation of clearance methods in the diseased kidney. J. Clin. Invest., 1941, 20, 631.

14. Raaschou, F., Studies of Chronic Pyelonephritis. Ejnar Munksgaard, Copenhagen, 1948.

15. Black, D. A. K., Platt, R., Rowlands, E. N., and Varley, H., Renal hæmodynamics in acute nephritis. Clinical Science, 1948, 6, 295.

16. Trueta, J., Barclay, A. E., Franklin, K. J., Daniel, P. M., and Prichard, M. M. L., Studies of the Renal Circulation. Charles C. Thomas, Springfield, 1947.

17. Cargill, W. H., and Black-Shaffer, B. C., Unpublished observations. 